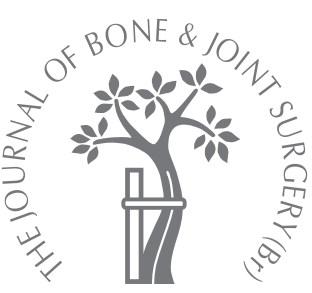

F. Kralinger, S. Unger, M. Wambacher, V. Smekal, W. Schmoelz

From Innsbruck Medical University, Innsbruck, Austria

\title{
The medial periosteal hinge, a key structure in fractures of the proximal humerus
}

\author{
A BIOMECHANICAL CADAVER STUDY OF ITS MECHANICAL \\ PROPERTIES
}

The medial periosteal hinge plays a key role in fractures of the head of the humerus, offering mechanical support during and after reduction and maintaining perfusion of the head by the vessels in the posteromedial periosteum. We have investigated the biomechanical properties of the medial periosteum in fractures of the proximal humerus using a standard model in $\mathbf{2 0}$ fresh-frozen cadaver specimens comparable in age, gender and bone mineral density. After creating the fracture, we displaced the humeral head medial or lateral to the shaft with controlled force until complete disruption of the posteromedial periosteum was recorded. As the quality of periosteum might be affected by age and bone quality, the results were correlated with the age and the local bone mineral density of the specimens measured with quantitative CT.

Periosteal rupture started at a mean displacement of $2.96 \mathrm{~mm}$ (SD 2.92) with a mean load of $100.9 \mathrm{~N}$ (SD 47.1). The mean maximum load of $111.4 \mathrm{~N}$ (SD 42.5) was reached at a mean displacement of $4.9 \mathrm{~mm}$ (SD 4.2). The periosteum was completely ruptured at a mean displacement of $34.4 \mathrm{~mm}$ (SD 11.1). There was no significant difference in the mean distance to complete rupture for medial (mean $35.8 \mathrm{~mm}$ (SD 13.8)) or lateral (mean $33.0 \mathrm{~mm}$ (SD 8.2)) displacement $(p=0.589)$.

The mean bone mineral density was $0.111 \mathrm{~g} / \mathrm{cm}^{3}$ (SD 0.035). A statistically significant but low correlation between bone mineral density and the maximum load uptake $(r=0.475$, $p=0.034$ ) was observed.

This study showed that the posteromedial hinge is a mechanical structure capable of providing support for percutaneous reduction and stabilisation of a fracture by ligamentotaxis. Periosteal rupture started at a mean of about $3 \mathrm{~mm}$ and was completed by a mean displacement of just under $35 \mathrm{~mm}$. The microvascular situation of the rupturing periosteum cannot be investigated with the current model.

\footnotetext{
F. Kralinger, MD, Trauma Surgeon

S. Unger, MD, Scientific Staff Member

M. Wambacher, MD, Trauma Surgeon

V. Smekal, MD, Trauma

Surgeon

W. Schmoelz, PhD, Head of Biomechanics

Department of Trauma Surgery and Sports Medicine

Innsbruck Medical University, Anichstrasse 35, A-6020

Innsbruck, Austria.

Correspondence should be sent to Dr F. Kralinger; e-mail: f.kralinger@uki.at
}

(C)2009 British Editorial Society of Bone and Joint Surgery doi:10.1302/0301-620X.91B7. $21857 \$ 2.00$

$J$ Bone Joint Surg $[\mathrm{Br}]$ 2009;91-B:973-6. Received 2 October 2008; Accepted after revision 8 April 2009

VOL. 91-B, No. 7, JULY 2009 has been postulated that the magnitude and direction of displacement of the humeral head seems to influence the integrity of the posteromedial periosteum. ${ }^{\text {? }}$

The aim of this study was to simulate a fracture of the humeral head below the anatomical neck with a calcar segment of reproducible length and to determine the displacement and force required to rupture the periosteum. We also wished to assess the effect of age and bone mineral density on the biomechanical properties of the periosteum.

\section{Materials and Methods}

We used 20 fresh-frozen human humeri acquired from subjects with a mean age of 72.4 years (43 to 89), of which 12 were male and eight female. Specimens were dissected leaving the muscle attachments intact. The shoulder capsule was divided as far from its insertion into well defined. In a non-peer-reviewed report it 


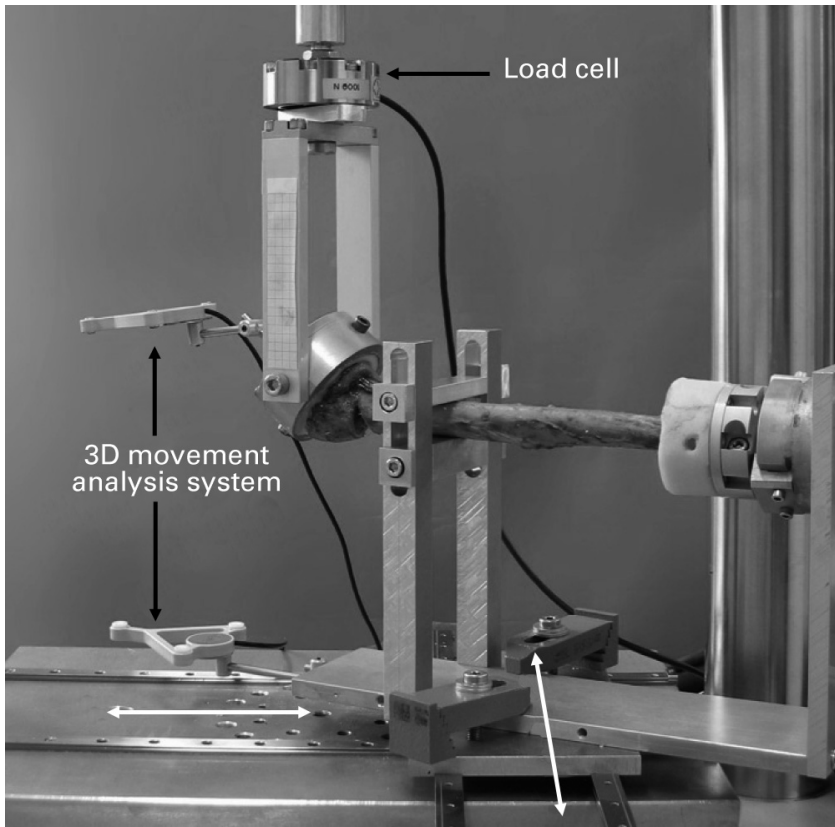

Fig. 1

Photograph showing test set-up in the material testing machine with the 3D movement analysis system and the load cell incorporated. White arrows indicate the two degrees of freedom permitted by the $x-y$ table.

the humerus as possible for maximum preservation of the medial soft-tissue envelope.

Prior to testing, a quantitative CT scan of all specimens was performed to assess the bone mineral density (BMD) and to exclude bony pathology. Specimens were stored at $-20^{\circ} \mathrm{C}$ and thawed at $4^{\circ} \mathrm{C}$ for 12 hours before testing, and randomly assigned into two groups for medial or lateral displacement. Each group consisted of six male and four female specimens. The mean age of those selected for lateral displacement was 74.1 years (64 to 89 ) with a mean BMD of $0.106 \mathrm{~g} / \mathrm{cm}^{3}$ (0.064 to 0.155$)$. The medial displacement group had a mean age of 70.7 years (43 to 89) with a mean BMD of $0.117 \mathrm{~g} / \mathrm{cm}^{3}$ (0.066 to 0.172 ).

The fracture models described in the literature did not seem appropriate for the purpose of the study, as they all used a complete osteotomy and sacrificed the medial soft tissue. ${ }^{8-13}$ We devised a new model with a complete bony rupture but intact medial soft tissues using 18 specimens in a pilot series. It was found that a valgus fracture model gave a reproducible calcar fracture with preservation of the periosteum.

In order to be able to create a predetermined fracture line with a reproducible length of calcar segment without injuring the medial periosteum, 20 dissected humeri were investigated. The location and number of the blood vessels entering the medial cortex via the foramina nutriciae at the anatomical neck were used to determine the area of the periosteum that should be left intact during creation of the fracture. In order to compensate for different humeral sizes, the area was normalised, based on the circumference of the medial centre of the humeral head, the most inferior point of the head and $18 \%$ anteriorly and $18 \%$ posteriorly.

In order to create the fracture this area was marked with two Kirschner wires $5 \mathrm{~mm}$ below the anatomical neck. The remaining dorsal part of the circumference of the head-neck junction was cut with an oscillating saw. Distal to the saw cut a wedge $10 \mathrm{~mm}$ in height was removed to create a predetermined breaking point.

The distal ends of the humeri were cut to a standard length of $25 \mathrm{~cm}$. In order to mount the specimen in the test set-up the proximal articulating surface and distal ends were embedded in polymethylmethacrylate (PMMA) cement (Technovit 3040, Heraus Kulzer, Werheim, Germany).

The testing. The biomechanical testing was conducted in a servohydraulic material testing machine (852 Mini Bionix II, MTS, Eden Prairie, Minnesota). The specimens were fixed in a custom-made jig mounted on an $x-y$ table to minimise shear forces. The jig allowed rotation of the humeral head in the anteroposterior (AP) axis through the centre of the head, which could be blocked after creation of the fracture (Fig. 1). For data acquisition a load cell $1000 \mathrm{~N}$ Kraftmessdose type KAT-S (AST GmbH, Dresden, Germany) and an ultrasound-based three-dimensional movement analysing system (Winbiomechanics, Zebris, Isny, Germany) were integrated in the test system. Force and displacement data were recorded with a sampling rate of $100 \mathrm{~Hz}$.

Fracture simulation. In all specimens a valgus fracture of the humerus was created approximately $12 \mathrm{~mm}$ distal to the anatomical neck. The head was loaded with a controlled displacement of $20 \mathrm{~mm} / \mathrm{min}$ until a fracture occurred, while rotation of the head in the AP axis was allowed (Fig. 2).

Rupture of the periosteum. After creating the fracture the head was restored to its intact position and rotation in the AP axis was blocked. The head fragment was then loaded with controlled displacement of $20 \mathrm{~mm} / \mathrm{min}$ in a medial $(n=10)$ or lateral $(n=10)$ direction until the medial periosteum at the calcar segment was disrupted.

After rupture of the periosteum the length of the calcar segment was measured and documented. From the recorded data load-displacement diagrams were obtained and analysed to identify the load and corresponding displacement at the start of the periosteal rupture, and the maximum load at the moment of complete rupture.

Statistical analysis. This was performed using the SPSS software package 15.0 (SPSS Inc., Chicago, Illinois). Data were tested for distribution using the KolmogorovSmirnov test. In order to analyse for differences in normally distributed values the $t$-test was used. Correlation of BMD with maximum load and age was analysed using a bivariate Pearson's test. The level of significance was set at $\mathrm{p}<0.05$. 


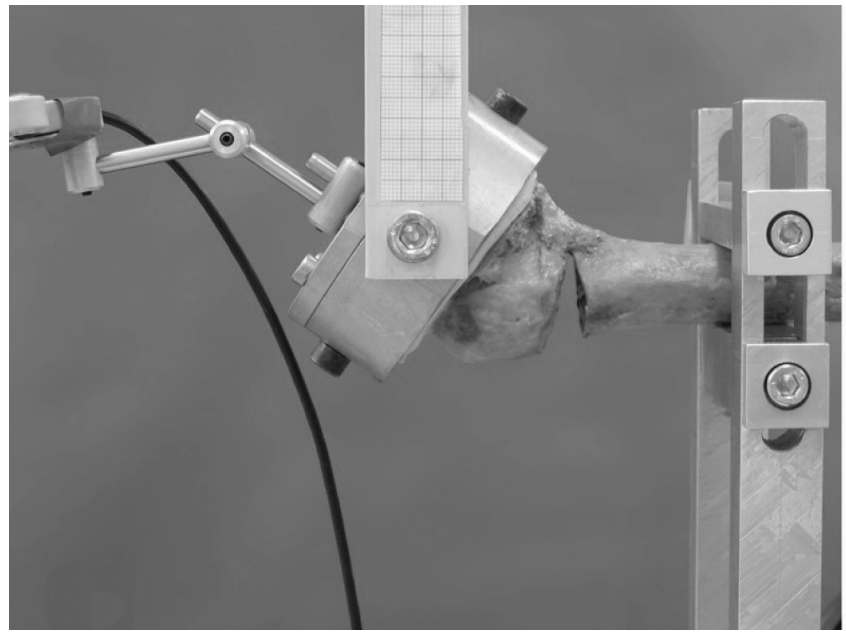

Fig. $2 a$

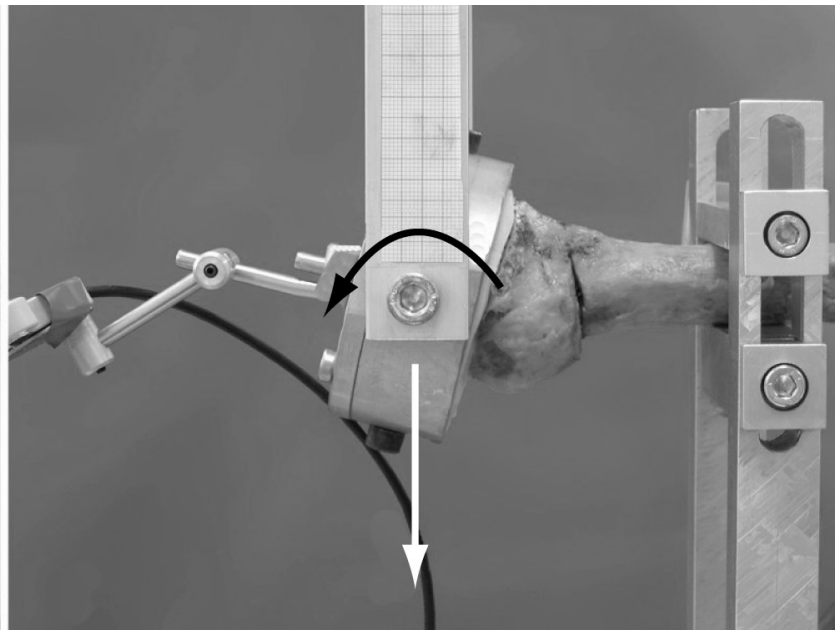

Fig. 2b

Photograph showing fracture creation in the loading jig showing a) the intact specimen and b) the fractured specimen. The white arrow indicates the displacement direction and the black arrow shows the rotation of the head allowed during fracture creation.

Table I. Descriptive values for medial and lateral displacement of the humeral head fragment.

\begin{tabular}{|c|c|c|c|c|c|c|}
\hline \multirow[b]{3}{*}{ Age (yrs) } & \multicolumn{3}{|c|}{ Medial displacement } & \multicolumn{3}{|c|}{ Lateral displacement } \\
\hline & \multirow{2}{*}{$\begin{array}{l}\text { Number } \\
10\end{array}$} & \multicolumn{2}{|c|}{ Mean (SD) } & \multirow{2}{*}{$\begin{array}{l}\text { Number } \\
10\end{array}$} & \multicolumn{2}{|c|}{ Mean (SD) } \\
\hline & & 70.7 & (13.49) & & 74.1 & (9.4) \\
\hline Bone mineral density $\left(\mathrm{g} / \mathrm{cm}^{3}\right)$ & 10 & 0.117 & $(0.037)$ & 10 & 0.106 & $(0.035)$ \\
\hline Length of calcar segment (mm) & 10 & 12.7 & $(2.6)$ & 10 & 12.6 & (3.3) \\
\hline Displacement at start of the periosteal rupture $(\mathrm{mm})$ & 10 & 2.4 & $(2.7)$ & 10 & 3.4 & (3.16) \\
\hline Load at start of the periosteal rupture $(\mathrm{N})$ & 10 & 85.16 & (41.9) & 10 & 116.6 & (48.8) \\
\hline Displacement at maximum load (mm) & 10 & 6.0 & (4.9) & 10 & 3.9 & $(3.2)$ \\
\hline Maximum load (N) & 10 & 103 & $(37.7)$ & 10 & 119.7 & $(47.2)$ \\
\hline Displacement at completed periosteal rupture (mm) & 10 & 35.88 & $(13.8)$ & 10 & 33 & (8.24) \\
\hline
\end{tabular}

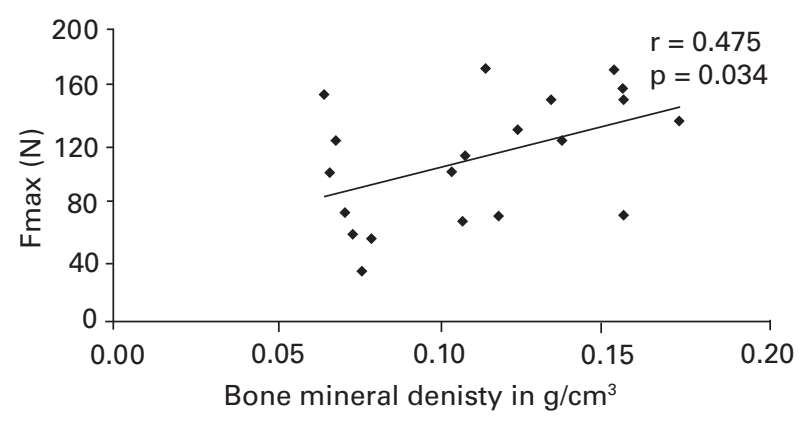

Fig. 3

Graph showing the correlation between maximum load uptake and bone mineral density.

\section{Results}

For all specimens periosteal rupture started at a mean displacement of $2.96 \mathrm{~mm}$ (SD 2.92) at a mean load of $100.9 \mathrm{~N}$ (SD 47.13). The mean maximum load of $111.4 \mathrm{~N}$ (SD 42.5) was reached at a mean displacement of $4.9 \mathrm{~mm}$ (SD 4.2).
The periosteum was completely ruptured at a mean displacement of $34.4 \mathrm{~mm}$ (SD 11.17). Regarding the two directions of displacement, medial displacement lead to full rupture at a mean distance of $35.8 \mathrm{~mm}$ (SD 13.8), whereas lateral displacement ended at a mean distance of $33 \mathrm{~mm}$ (SD 8.2). None of the measured parameters of load and displacement at the start and after complete rupture were statistically significant between the two directions of displacement $(0.139<\mathrm{p}<0.589)$. Descriptive values for both directions are given in Table I.

Study of the 20 dissected specimens revealed that the nutrient foramena responsible for the vascularity of the humeral head extended distally along the medial cortex for a distance of $40 \mathrm{~mm}$ to $55 \mathrm{~mm}$ depending on the overall size of the humerus. Applying the normalisation based on the circumference of the anatomical neck this involved $36 \%$ (SD 4) of that circumference.

The mean BMD was $0.111 \mathrm{~g} / \mathrm{cm}^{3}$ (SD 0.035). A statistically significant correlation between BMD and the maximum load uptake $(\mathrm{r}=0.475, \mathrm{p}=0.034)$, as well as between BMD and age $(r=-0.715, \mathrm{p}=0.0001)$ was observed (Fig. 3 ). No correlation was found between age and maximum load 
uptake $(\mathrm{r}=-0.383, \mathrm{p}=0.1)$. The distances at the beginning and endpoint of rupture were not statistically related to BMD. Furthermore, it was found that specimens younger than 70 years had a higher BMD $(\mathrm{p}=0.0001)$ and a higher maximum load $(\mathrm{p}=0.016)$ than specimens of 70 years and older. The age of 70 years was chosen as the cut off as this was the median age of the investigated samples.

\section{Discussion}

Periosteal bridges between the head fragment and the shaft can preserve the blood supply of the head in complex fractures. ${ }^{2,3}$ In this study we found that periosteal rupture starts after displacement of the humeral head fragment of approximately $3 \mathrm{~mm}$, and is completed after a displacement of approximately $34 \mathrm{~mm}$, without any significant difference between medial or lateral displacement. This contrasts with the results of Resch and Hubner, ${ }^{7}$ who found a significant difference between medial or lateral displacement of the head fragment, with the periosteal rupture commencing at $9 \mathrm{~mm}$ and $6 \mathrm{~mm}$ displacement, respectively. The difference in the results can probably be explained by the difference in the experimental models. Resch and Hubner ${ }^{7}$ did not describe their method of fracture creation prior to displacement of the humeral head, how the head segment was displaced, or how the start of periosteal rupture was assessed, as no load was recorded during head displacement.

Our pilot study established that creating a breaking point $5 \mathrm{~mm}$ distal to the anatomical neck reproducibly caused a fracture with a medial calcar extension $>8 \mathrm{~mm}$.

Reproducibility of the length of the calcar segment was considered important, as several studies have shown a correlation between its size and its influence on the vascularity of the head fragment, ${ }^{3-6}$ including the site of some of the foramen nutriciae. All the fracture models found in the literature are based on full osteotomies of the proximal humerus. ${ }^{8-13}$

A limitation of our study was that we tested only with medial and lateral displacement, not allowing ante- or retroversion during creation of the fracture and displacement of the head. Therefore, the effect of combined displacements could not be investigated. Also, the size of the calcar fragment was not exactly the same in all samples, leaving some uncertainty about the influence of the length of attached periosteum on the disruption of the blood supply.

There is a lack of information correlating the mechanical properties of the periosteum with the BMD. The correlation between BMD and load uptake shown in this study is low. Considering the thick periosteum found in children and the thin and fragile material seen intra-operatively when treating elderly patients, a strong correlation might be anticipated. Further studies with a larger sample size are required to investigate this further.

Bone quality influences the bone implant interface performance, as shown in biomechanical studies. ${ }^{14-16}$ Scientific evidence of the influence of the BMD on fracture fixation is still lacking, ${ }^{17}$ but most surgeons managing osteoporotic fractures are familiar with possible problems of fixation in low-quality bone. The ligamentotaxis effect can provide mechanical support in reduction and stabilisation of a fracture until healing is achieved. ${ }^{1,7,18,19}$ In this study the mean maximum load uptake prior to periosteal rupture was $111.4 \mathrm{~N}$, supporting the use of ligamentotaxis. However, it is not known whether the blood vessels in the posteromedial soft tissue would rupture before the periosteum tears. Finally, radiological assessments of fracture characteristics are conducted on plain films, which provide no information on the maximum displacement that occurred during the trauma. Therefore, determination of periosteal integrity on the basis of displacement on plain radiographs is unrealistic.

No benefits in any form have been received or will be received from a commercial party related directly or indirectly to the subject of this article.

\section{References}

1. Jaberg H, Jakob RP. Compound fractures of the proximal humerus. Orthopade 1987;16:320-35 (in German).

2. Bogner R, Hubner C, Matis $\mathbf{N}$, et al. Minimally-invasive treatment of three- and fourpart fractures of the proximal humerus in elderly patients. $J$ Bone Joint Surg $[\mathrm{Br}]$ 2008;90-B:1602-7.

3. Robinson CM, Khan LA, Akhtar MA. Treatment of anterior fracture-dislocations of the proximal humerus by open reduction and internal fixation. J Bone Joint Surg $[\mathrm{Br}]$ 2006;88-B:502-8.

4. Brooks CH, Revell WJ, Heatley FW. Vascularity of the humeral head after proximal humeral fractures: an anatomical cadaver study. J Bone Joint Surg [Br]1993;75-B:132-6.

5. Meyer C, Alt V, Hassanin H, et al. The arteries of the humeral head and their relevance in fracture treatment. Surg Radiol Anat 2005;27:232-7.

6. Hertel R, Hempfing A, Stiehler M, Leunig M. Predictors of humeral head ischemia after intracapsular fracture of the proximal humerus. J Shoulder Elbow Surg 2004;13:427-33.

7. Resch H, Hubner C. Percutaneous treatment of proximal humeral fractures. In: Leune WN, Marra G, Bigliani LU, eds. Fractures of the shoulder girdle. New York: Marcel Dekker, 2003:33-54.

8. Lill H, Hepp P, Korner J, et al. Proximal humeral fractures: how stiff should an implant be?: a comparative mechanical study with new implants in human specimens. Arch Orthop Trauma Surg 2003;123:74-81.

9. Hessmann MH, Korner J, Hofmann A, Sternstein W, Rommens PM. Angle-fixed plate fixation or double-plate osteosynthesis in fractures of the proximal humerus: a biomechanical study. Biomed Tech (Berl) 2008;53:130-7 (in German).

10. Carrera EF, Nicolao FA, Netto NA, et al. A mechanical comparison between conventional and modified angular plates for proximal humeral fractures. J Shoulder Elbow Surg 208;17:631-6.

11. Fuchtmeier B, May R, Hente R, et al. Proximal humerus fractures: a comparative biomechanical analysis of intra and extramedullary implants. Arch Orthop Trauma Surg 2007:127:441-7.

12. Edwards SL, Wilson NA, Zhang LQ, Flores S, Merk BR. Two-part surgical neck fractures of the proximal part of the humerus: a biomechanical evaluation of two fixation techniques. J Bone Joint Surg [Am]2006;88-A:2258-64.

13. Wals $\mathbf{S}$, Reindl $\mathbf{R}$, Harvey $\mathbf{E}$, et al. Biomechanical comparison of a unique locking plate versus a standard plate for internal fixation of proximal humerus fracture in a cadaveric model. Clin Biomech (Bristol, Avon)2006;21:1027-31.

14. Schoenfeld AJ, Battula S, Sahai V, et al. Pullout strength and load to failure properties of self-tapping cortical screws in synthetic and cadaveric environments representative of healthy and osteoporotic bone. J Trauma 2008;64:1302-7.

15. Seebeck J, Goldahn J, Morlock MM, Schneider E. Mechanical behavior of screws in normal and osteoporotic bone. Osteoporos Int 2005;16(Suppl 2):107-11.

16. Seebeck J, Goldhahn J, Städele H, et al. Effect of cortical thickness and cancellous bone density on the holding strength of internal fixator screws. J Orthop Res 2004;22:1237-42.

17. Goldhahn J, Suhm N, Goldhahn S, Blauth M, Hanson B. Influence of osteoporosis on fracture fixation: a systematic literature review. Osteoporos Int 2008;19:761-72.

18. Resch H, Hubner C, Schwaiger R. Minimally invasive reduction and osteosynthesis of articular fractures of the humeral head. Injury 2001;32(Suppl 1):25-32.

19. Resch H, Beck E, Bayley I. Reconstruction of the valgus-impacted humeral head fracture. J Shoulder Elbow Surg 1995;4:73-80. 